\title{
¿Ciudades sustentables o ciudades que contribuyen al desarrollo sustentable?*
}

\section{David Satterthwaite**}

Este articulo esboza un marco para evaluar el desempeño ambiental de las ciudades en relación con el cumplimiento de las metas del desarrollo sustentable. También considera la manera como éstas se ajustan a las metas sociales, económicas y políticas del desarrollo sustentable y menciona las estructuras nacionales y contextos internacionales necesarios para estimular a los consumidores, empresas y gobiernos urbanos a progresar hacia su cumplimiento. En una sección final se considera el grado al cual las recomendaciones de la conferencia Hábitat TLayudaron a estimular a los gobiernos nacionales y a las autoridades urbanas y municipales para cumplir con esos propósitos.

\section{Introducción}

Los últimos diez años han ofrecido ejemplos de considerable innovación entre las autoridades urbanas y municipales de muchas partes del mundo en lo referente al desarrollo sustentable. En Europa y Norteamérica muchas ciudades han emprendido programas a largo plazo para mejorar su ambiente y reducir el uso de recursos y generación de desechos (Mega, 1996a; United Nations Comission On Human Settlements, 1996; Comisión Europea, 1994). Cada vez más ciudades tienen autoridades que se han comprometido con las metas del desarrollo sustentable -como en la Campaña Europea de Ciudades y Pueblos Sustentables- y que han mostrado una mayor disposición a compartir su conocimiento y experiencias con otras autoridades urbanas (Mega, 1996a; unchs, 1996). Ciertas ciudades latinoamericanas también han emprendido programas a largo plazo para abordar los problemas ambientales -como Curitiba en Brasil (Rabinovitch, 1992) o lio en Perú (Díaz, López Follegati y Hordijk, 1996)-, mientras que

* Este artículo fue publicado en inglés en: Urban Studies, vol. 34, núm. 10, 1997. El texto se apoya en el trabajo que el autor emprendió con la Organización Mundial de la Salud para preparar dos documentos cuyos resultados se utilizan aquí (oms, 1992; oMs, 1996), así como en el trabajo que realizó para preparar unchs, 1996. El autor agradece particularmente a Sam Ozolins, Greg Goldstein y Wilfrid Kreisel de la oms y Donatus Okpala de unchs por su ayuda. Agradece también a Cedric Pugh, Diana Mitlin, Nick Robins y Koy Thomson por sus comentarios sobre una versión anterior. Traducción de Lucrecia Oresanz.

** Editor de la revista Environment and Urbanization del International Institute for Environment and Development (IED). 
en muchas ciudades de todo el mundo ha habido una innovación considerable por parte de las autoridades en la forma de abordar los problemas ambientales. También hay un movimiento mundial de ciudades saludables, en el cual las autoridades de más de mil ciudades han buscado nuevas formas de trabajar con los distintos actores e intereses, para promover la salud y prevenir la enfermedad (oms, 1996).

La discusión sobre el desarrollo sustentable en relación con las ciudades también ha recibido un mayor reconocimiento oficial. Por ejemplo, los términos ciudades sustentables y asentamientos humanos sustentables fueron muy notorios en Hábitat II, la segunda conferencia de la oNU sobre asentamientos humanos (también conocida como Cumbre de la Ciudad), celebrada en Estambul en :junio de 1996. A pesar de los desacuerdos entre los distintos grupos representados en la conferencia -por ejemplo, entre la Unión Europea, el grupo de los 77 y Estados Unidos-, todas las delegaciones gubernamentales parecieron apoyar la idea de asentamientos humanos sustentables o desarrollo urbano sustentable.

Pero esta aparente unanimidad es engañosa, porque no hubo ninguna definición clara y acordada en cuanto a lo que significan esos términos. Se ha incluido un rango tan amplio de metas ambientales, económicas, sociales, políticas, demográficas, institucionales y culturales como parte del desarrollo sustentable, que la mayoría de los gobiernos o agencias internacionales pueden caracterizar lo que hacen como una contribución a éste. Esto puede incluir metas cuyo logro en un sector o localidad implica alejarse de su logro en otro. Por ejemplo, una razón por la que puede mejorar la calidad ambiental de las ciudades ricas es porque sus consumidores y productores pueden importar todos los bienes cuya producción requiere altos niveles de uso de recursos y generalmente incluye altos niveles de generación de desechos (provocando serios problemas con residuos peligrosos), contaminación y riesgo ambiental para su fuerza de trabajo (Satterthwaite, 1997).

Los gobiernos de las naciones más ricas del mundo también pueden apoyar la noción de ciudades sustentables sin admitir que son los consumidores y empresas de sus ciudades los que tienen que hacer las mayores reducciones en el uso de recursos y generación de desechos. Además, la mayoría de los gobiernos del norte continúa concibiendo el crecimiento económico como el principal medio para reducir el desempleo y aumentar los ingresos y es difícil, si no imposible, combinar esto con disminuciones significativas en el uso de recursos no re- 
novables y generación de gases de invernadero, a menos de que haya una vinculación explícita entre la generación de empleo y estas metas. El logro simultáneo de las metas sociales y ambientales inherentes a la definición de desarrollo sustentable de la Comisión Brundtland (satisfacer las necesidades del presente sin comprometer la capacidad de las generaciones futuras para satisfacer sus propias necesidades) implica políticas muy diferentes para reducir el desempleo y aumentar los ingresos entre aquéllos con ingresos inadecuados - que enfrentan el problema más directamente que el "escurrimiento" del crecimiento económico y que favorecen un menor uso y desperdicio de recursos. Si bien muchos gobiernos nacionales pueden asegurar que están promoviendo el desarrollo sustentable, pocos han comenzado a poner en práctica un marco fiscal e institucional que apoye un acercamiento al logro del conjunto completo de las metas del desarrollo sustentable en las áreas urbanas (y rurales) dentro de sus fronteras (véase por ejemplo O'Riorden, 1989; Haughton y Hunter, 1994).

Esta falta de progreso entre las naciones del norte desanima el progreso entre las naciones del sur. El hecho de que el sur incluye a tres cuartas partes de la población mundial y una proporción grande y creciente de la actividad económica y de los grandes consumidores a nivel mundial, también implica una participación grande y creciente en el uso global de recursos, generación de desechos y emisión de gases de invernadero. Pero a pesar de la diversidad de naciones en el sur, en conjunto ellas señalan que los niveles de uso de recursos, generación de desperdicios y emisión de gases de invernadero por persona son más altos en el norte, así como sus contribuciones históricas a estos problemas. Sin un compromiso serio por parte de los gobiernos del norte para reducir el uso de recursos, generación de desperdicios y emisión de gases de invernadero, así como para apoyar el cumplimiento de las metas del desarrollo sustentable en el sur, los gobiernos del sur estarán reticentes a actuar. Esto aplaza las acciones por medio de las cuales se podría lograr que los patrones de asentamiento y los sistemas de transporte de las naciones con una urbanización con frecuencia rápida se volvieran menos dependientes de altos niveles de uso de automóviles particulares, y sus construcciones menos dependientes de altos niveles de energía para iluminación y calefacción o refrigeración. Como se discutirá con mayor detalle más adelante, es difícil ajustar los edificios, patrones de asentamiento y sistemas de transporte que se desarrollaron durante el largo periodo de petróleo barato y prosperidad generalmente creciente, a niveles 
mucho más bajos de uso de combustibles fósiles. Pero en las naciones que se están urbanizando rápidamente, establecer un marco institucional y regulativo que estimule la conservación de energía en todos los sectores, minimice la necesidad de calefacción o refrigeración en los edificios y promueva patrones de asentamiento que limiten la necesidad de altos niveles de uso particular de automóviles, puede asegurar el desarrollo de ciudades más compatibles con algunas de las principales metas del desarrollo sustentable. Un marco que estimule el uso eficiente del agua en todos los sectores y que promueva la reutilización de las aguas residuales de manera apropiada también puede reducir considerablemente la perspectiva de una escasez de agua.

La ambigũedad en cuanto a lo que significa ciudades sustentables o asentamientos humanos sustentables también permite que muchas de las grandes agencias internacionales aseguren ser líderes en la promoción de ciudades sustentables, cuando en realidad han contribuido en gran medida al crecimiento de ciudades donde no se cumplen las metas del desarrollo sustentable. Por ejemplo, la mayoría de las agencias internacionales da poca prioridad a la satisfacción directa de las necesidades humanas (como el suministro suficiente y seguro de agua, saneamiento, educación primaria y atención a la salud). La mayoría también da poca prioridad (o no asigna nada) a mejorar la recolección y disposición de basura, conservación de energía y transporte público en las ciudades, a pesar de su importancia para el cumplimiento de las metas del desarrollo sustentable. ${ }^{1}$

Este artículo plantea que para poder progresar hacia el cumplimiento de las metas del desarrollo sustentable, el desempeño ambiental de las ciudades tiene que mejorar no sólo en términos de una mejor calidad ambiental dentro de sus límites, sino también en términos de reducir la transferencia de costos ambientales hacia otra gente, otros ecosistemas o hacia el futuro. Esto plantea considerables dificultades institucionales para las autoridades municipales y urbanas, cuyas responsabilidades oficiales son para con sus propios ciudadanos. En un mercado mundial competitivo es difícil para las autoridades de una ciudad reconciliar la necesidad de atraer o retener nuevas inversiones con un compromiso con el rango completo de las metas del desarrollo sustentable, especialmente aquellas que elevan los gastos

${ }^{1}$ La IIED evalúa la prioridad que las agencias internacionales otorgan a la satisfacción de necesidades básicas y al desarrollo urbano. Un resumen de los hallazgos de su trabajo con ese propósito se publicó en UNCHs, 1996. 
dentro de la ciudad para reducir los costos ambientales de la gente fuera de esas ciudades. Éste es un tema al cual se regresará en este artículo, después de describir un marco de referencia para evaluar el desempeño ambiental de las ciudades.

Un marco de referencia para considerar el desempeño ambiental de las ciudades

La dificultad de comparar el desempeño ambiental entre centros urbanos distintos

Quizás la principal dificultad con la que se enfrenta cualquier investigador o institución que quiera comparar el desempeño ambiental de distintas ciudades (incluyendo las del norte y sur) es el rango de los problemas que se consideran ambientales. Por ejemplo, desde la perspectiva de la salud ambiental, las ciudades del norte se desempeñan mucho mejor para sus habitantes que la mayoría de las ciudades del sur, como puede verse en la participación mucho menor de los riesgos ambientales en la enfermedad, lesiones y muerte prematura (oms, 1996; UNCHS, 1996). Pero desde la perspectiva de los niveles promedio de uso de recursos, generación de desperdicios o emisión de gases de invernadero por persona, la mayoría de las ciudades del sur tiene niveles mucho menores que las ciudades del norte (Hardoy, Mitlin y Satterthwaite, 1992; uncHs, 1996).

También está la dificultad de saber cómo:juzgar el desempeño ambiental de las ciudades cuando la alta calidad ambiental en muchas de ellas se logra en parte por la transferencia de problemas ambientales hacia otras personas o localidades. Por ejemplo, los sistemas de drenaje que alejan las aguas residuales de la ciudad aportan importantes ventajas ambientales a los habitantes y empresas de esa ciudad, pero si se dispone de ellas sin tratamiento en cuerpos de agua cercanos, se le provocan serios costos ambientales y económicos a otros -como cuando se dañan las pesquerías locales o cuerpos de agua que dejan de ser adecuados para su uso río abajo. La transferencia de costos ambientales también puede darse a través de distancias mucho más grandes o hacia el futuro.

Esto sugiere la necesidad de distinguir diferentes tipos de problemas ambientales entre ciudades, de modo que se comparen cosas de la misma clase. Pero existe el peligro de que así las comparaciones entre 
ciudades en cuanto al desempeño ambiental se reduzcan a los indicadores que se miden con facilidad. Por ejemplo, es más fácil conseguir información sobre la concentración de ciertos contaminantes del aire en grandes ciudades del sur, como dióxido de azufre, que sobre la proporción de su población con un suministro adecuado de agua potable y saneamiento o sobre la contribución de los accidentes viales al índice de lesiones y muertes prematuras. Esto implica que las discusiones sobre concentraciones de dióxido de azufre reciben más atención de la que merecen dentro de las discusiones sobre riesgos ambientales en las ciudades, mientras que el suministro inadecuado de agua y saneamiento y el control inadecuado de los accidentes de tránsito reciben atención insuficiente. Al evaluar el desempeño ambiental de las ciudades es necesario distinguir entre los distintos problemas ambientales, así como buscar una cobertura más completa de todos estos problemas, incluyendo aquellos para los cuales hay poca información. También es necesario asegurar que el desempeño ambiental mejorado sea uno que no se dé a expensas del desempeño ambiental de otros.

En el compromiso con el desarrollo sustentable hay cinco categorías amplias de acción ambiental dentro de las cuales debe evaluarse el desempeño de todas las ciudades. Éstas son:

1) Controlar las enfermedades infecciosas y parasitarias y la carga que representan para las poblaciones de la ciudad, incluyendo la reducción de la vulnerabilidad de estas poblaciones ante dichas enfermedades. Esto suele denominarse "agenda café" o agenda sanitaria, pues incluye la necesidad de asegurar un suministro adecuado de agua, saneamiento, drenaje y recolección de basura para todos los habitantes y empresas de la ciudad. Debe incluir más que esto: por ejemplo, controlar las enfermedades infecciosas y parasitarias que no están asociadas con un servicio inadecuado de agua o saneamiento, incluyendo las infecciones respiratorias agudas (la principal causa de muerte en el nivel mundial), tuberculosis (la principal causa de muerte en adultos en el nivel mundial) y las enfermedades transmitidas por animales o insectos como vectores.

2) Reducir los riesgos químicos y físicos en el hogar, lugar de trabajo y ciudad en conjunto.

3) Lograr un ambiente urbano de alta calidad para todos los habitantes de la ciudad, por ejemplo, en cuanto a la cantidad y calidad de espacios al aire libre por persona (jardines públicos, parques, instalaciones deportivas y recreativas) y la protección de la herencia natural y cultural. 
4) Minimizar la transferencia de costos ambientales a los habitantes y ecosistemas que rodean a la ciudad; $y$

5) Asegurar el progreso hacia lo que suele llamarse como consumo sustentable, es decir, asegurar que los bienes y servicios necesarios para satisfacer las necesidades de consumo de todos sean obtenidos sin minar el capital ambiental de las naciones y del mundo. Esto implica por parte de las empresas y los habitantes de la ciudad que su uso de recursos, consumo de bienes importados y generación y disposición de desperdicios sean compatibles con los límites del capital natural y no transfieran costos ambientales a otras personas (incluyendo generaciones futuras).

Las primeras tres categorías pueden considerarse los aspectos ambientales de la satisfacción de necesidades de los habitantes de la ciudad. Son parte de las obligaciones convencionales de las autoridades locales -aunque hay una gran variedad en cuanto a las formas en que las autoridades locales promueven su cumplimiento. La cuarta y quinta son más problemáticas, pues conciernen impactos ambientales que en general ocurren fuera de la:jurisdicción de las autoridades locales responsables del manejo ambiental de las ciudades.

Separar la evaluación del desempeño ambiental de las ciudades en estas cinco categorías permite considerar los elementos comunes que comparten todas las ciudades, con un entendimiento de cómo deben diferir las prioridades. Por ejemplo, quizás la principal prioridad ambiental en la mayoría de las ciudades del norte sea reducir los niveles de uso de recursos, generación de desperdicios y emisión de gases de invernadero, manteniendo o mejorando a la vez la calidad del ambiente urbano. Pero esto no implica descuidar los otros aspectos -por ejemplo, en la mayoría de las ciudades queda mucho por hacer para reducir los riesgos físicos (como los causados por vehículos motorizados) y los contaminantes químicos- y, como se esboza más adelante, también hay nuevas amenazas que enfrentar en el control de enfermedades infecciosas. Además, en la mayoría de las ciudades del norte aún hay una proporción de la población que vive o trabaja con niveles inaceptables de riesgo ambiental. En cambio, las prioridades ambientales de la mayoría de las ciudades pequeñas de los países más pobres del sur se centrarán en las primeras dos categorías -aunque el hecho de integrar a sus planes urbanos una preocupación por un ambiente urbano de alta calidad, un uso eficiente de recursos, un buen manejo de desechos líquidos y sólidos y una minimización de las emisiones de gases de invernadero ofrecerá muchas ventajas a largo plazo. Considerar el desempeño ambiental de las ciudades a lo largo 
de las cinco categorías también ayuda a aclarar la manera como cambian los problemas ambientales para las ciudades que crecen y/o se enriquecen cada vez más (Bartone et al., 1994; Satterthwaite, 1997).

\section{Control de enfermedades infecciosas y parasitarias}

Por el hecho de concentrar a la gente y las actividades económicas, las ciudades tienen muchas ventajas, a diferencia de un patrón de asentamiento más disperso, en cuanto al control de las enfermedades infecciosas y parasitarias -especialmente por la concentración de gente que reduce los costos unitarios de muchas formas de infraestructura (agua entubada, drenaje y la mayoría de las formas de saneamiento) y servicios (incluyendo atención a la salud, servicios de emergencia y recolección de basura). Cuando se hace una buena administración de la salud pública y la salud ambiental y todos los sectores de la sociedad urbana contribuyen a la salud, las ciudades pueden ser de los lugares más saludables para vivir (oms, 1996).

Pero en ausencia de tal administración, hay muchas enfermedades infecciosas y parasitarias que prosperan cuando los servicios de agua, saneamiento, drenaje, recolección de basura y atención a la salud son inadecuados o se interrumpen. Como resultado, las ciudades se convierten en uno de los ambientes humanos más peligrosos para la salud, en la medida en que se multiplican los vectores y los agentes causantes de enfermedades, ya que la gran concentración de gente que vive muy cerca una de otra aumenta el riesgo de transmisión de enfermedades y que los sistemas de atención a la salud se vuelven incapaces de responder rápida y eficazmente. Si los servicios de saneamiento, drenaje y recolección de basura se interrumpen o no logran mantenerse al nivel de la creciente población urbana, se incrementan en gran medida los riesgos a la salud, especialmente en relación con las diversas enfermedades diarreicas y otras transmitidas por los excrementos humanos, así como las transmitidas por vectores que se crían o se alimentan en la basura no recolectada o en el agua estancada (como paludismo, filariasis, fiebre amarilla y dengue, en los climas donde pueden sobrevivir las especies de mosquitos que constituyen sus vectores). En un momento dado, cerca de la mitad de la población urbana del sur padece una o más de las principales enfermedades asociadas con un suministro inadecuado de agua o saneamiento (oms, 1996). Si los sistemas de salud se interrumpen o no logran man- 
tenerse al nivel del crecimiento poblacional, se amplifican los problemas de salud de quienes se enferman -por ejemplo, las infecciones respiratorias agudas están entre las principales causas de muerte infantil, aunque son fáciles de curar si se detectan y tratan de forma adecuada. Además, si los sistemas de salud no pueden realizar programas de vacunación, las enfermedades como sarampión y difteria pueden volverse causas importantes de muerte.

Casi todas las ciudades también concentran grandes cantidades de personas particularmente vulnerables a la infección. Por ejemplo, la mayoría de las ciudades del sur tiene altas proporciones de niños cuyos sistemas inmunológicos no se han desarrollado para protegerlos de enfermedades infecciosas comunes. En muchas de estas ciudades una gran proporción de niños (y adultos) tiene sistemas inmunológicos amenazados por la desnutrición y las infestaciones de lombrices. Muchas ciudades o distritos urbanos en el norte y algunos en el sur también tienen una alta concentración de ancianos, que son más vulnerables a muchas enfermedades infecciosas. La mayoría de las ciudades también tiene un constante movimiento de entrada y salida de gente, lo cual puede implicar la llegada de personas con infecciones nuevas, ante las cuales la población local no es inmune (oMs, 1996).

Hay dos problemas adicionales. El primero es el creciente número de lo que generalmente se llaman enfermedades nuevas o emergentes, de las cuales el sida es la mejor conocida y una de las más extendidas. Son nuevas en el sentido de que sólo recientemente se han vuelto un problema significativo de salud pública, aunque en la mayoría de los casos lo que es nuevo es su incidencia y alcance geográfico, ya que previamente habian existido ya sea en la naturaleza o en comunidades aisladas (oms, 1996). El segundo problema es la reaparición de enfermedades infecciosas conocidas que hasta hace poco se consideraban controladas. Por ejemplo, ahora el cólera y la fiebre amarilla están invadiendo zonas que se habían creído inmunes. El paludismo y el dengue se han convertido en dos de los problemas de salud más serios en muchos centros urbanos. La tuberculosis sigue siendo la principal causa de muerte en adultos a nivel mundial $-\mathrm{y}$ su incidencia ha aumentado rápidamente en la última década, tanto en el norte como en el sur. La razón por la que las enfermedades nuevas y reemergentes se han vuelto un problema tan serio es la poca prioridad concedida por la mayoría de los gobiernos y agencias internacionales a la salud pública y atención a la salud. Pero parte de la razón también son las mayores dificultades para prevenir y controlar las enfermedades 
infecciosas a medida que las sociedades se urbanizan y aumentan los movimientos poblacionales (incluyendo el rápido incremento en el número de gente que cruza fronteras internacionales), y a medida que los agentes que causan las enfermedades desarrollan resistencias ante las medidas de salud pública o se adaptan a las cambiantes circunstancias ecológicas en formas que aumentan los riesgos de infección para las poblaciones humanas. Por ejemplo, el control del paludismo se ha vuelto más difícil en muchos lugares porque los mosquitos anopheles ya son resistentes a muchos insecticidas y ya no son efectivos muchos de los medicamentos usados para tratar o prevenir el paludismo. Varias especies de anófeles también han mostrado ser capaces de adaptarse a los ambientes urbanos (oms, 1992, 1996). Asimismo, muchos agentes bacterianos causantes de enfermedades, incluyendo los que provocan la neumonía, tuberculosis, fiebres tifoideas y algunas enfermedades diarreicas y formas de intoxicación por comida, se han vuelto resistentes a muchos antibióticos (oms, 1996). Mientras tanto, el desarrollo y distribución de nuevos antibióticos no puede igualar la velocidad con la cual los agentes causantes de enfermedad desarrollan resistencias, y menos aún en los países más pobres del sur (Leduc y Tikhomirov, 1994).

La urbanización también crea focos para los vectores y nuevos nichos ecológicos para animales que albergan agentes infecciosos o vectores. Esto puede resultar de la expansión de áreas construidas, de la construcción de caminos, embalses y drenajes y del desmonte y deforestación de tierras (oms, 1996) o de los crecientes volúmenes de excrementos humanos, basura y aguas residuales de los que no se dispone. Además, a medida que se expanden las ciudades, es común que los grupos de bajos ingresos establezcan asentamientos en terrenos sujetos a inundaciones o sobre o cerca de humedales, ya que estas tierras tienen menor valor comercial y los habitantes tienen mayores probabilidades dé que se les permita quedarse ahí. Pero esto también puede implicar una mayor cercanía a sitios de crianza de varios insectos vectores, arriesgando a los habitantes a contagiarse de paludismo (por los mosquitos anopheles) o dengue o fiebre amarilla (por los mosquitos aedes).

Los medios para reducir en gran medida estos problemas son bien conocidos y se han aplicado desde hace mucho en ciudades del norte y en algunas ciudades del sur. En tales ciudades, aunque algunas enfermedades nuevas y reemergentes están causando serias dificultades para las autoridades públicas, la contribución de las enfermedades infecciosas y parasitarias a los problemas de salud o muerte prematura se ha reducido enormemente. Frecuentemente se olvida 
la velocidad de esta transformación en la salud de las poblaciones urbanas. Ha sido sólo en los últimos cien años que las sociedades han desarrollado el conocimiento, capacidad y competencia para protegerse de las enfermedades que antes proliferaban, sobre todo en las ciudades. Esto puede comprobarse en las tasas de mortalidad infantil que existian hace tan sólo cien años en las ciudades más prósperas del mundo. Hoy en día dichas tasas en las ciudades saludables y con buenos servicios son de alrededor de 10 por cada 1000 nacidos vivos, y es muy raro que un niño muera por una enfermedad infecciosa o parasitaria. La mayoría de las ciudades europeas prósperas de hace cien años todavía tenían tasas de mortalidad infantil superiores a 100 por cada 1000 nacidos vivos; en Viena, Berlín, Leipzig, Nápoles, San Petersburgo y muchas de las grandes ciudades industriales de Inglaterra esta cifra excedía los 200, y en Moscú los 300 (Bairoch, 1986; Wohl, 1983).

En casi todo el sur queda mucho por hacer. En muchas de sus ciudades o en las zonas urbanas donde viven los grupos de bajos ingresos siguen siendo comunes las tasas de mortalidad infantil de 100 o más por cada 1000 nacidos vivos. Son comunes tasas aún más altas en asentamientos informales o ilegales donde hay un suministro inadecuado de agua, saneamiento y servicios de salud. Una estimación de 1990 sugería que 600 millones de habitantes urbanos del sur vivían en casas y barrios donde sus vidas y salud estaban constantemente amenazadas por el inadecuado e insuficiente suministro de agua, saneamiento, recolección de desechos sólidos y líquidos y servicios de salud y emergencias (Cairncross, Hardoy y Satterthwaite, 1990; oms, 1992).

Reducción de riesgos quimicos y fisicos en la casa, el lugar de trabajo y la ciudad en general

La escala y severidad de muchos riesgos químicos y físicos aumentan rápidamente con la creciente producción industrial y con el aumento del tránsito vehicular. Mientras que el control de las enfermedades infecciosas o parasitarias y la reducción de la vulnerabilidad de la población ante dichas enfermedades se centra en el suministro de infraestructura y servicios a poblaciones urbanas completas (ya sea por medio de instituciones públicas y privadas, organizaciones no gubernamentales $u$ organizaciones comunitarias), el progreso en esta segunda categoría se logra en gran medida regulando las actividades de 
las empresas y de los individuos. Probablemente el factor más importante en términos de mejorar la salud sea el control de los riesgos laborales, que incluyen exposición de las personas a concentraciones peligrosas de químicos y polvos, iluminación, ventilación y espacio inadecuados y falta de protección ante maquinaria y ruidos. Es necesario actuar en estas áreas desde las grandes fábricas hasta los pequeños talleres caseros (oMs, 1996).

Uno de los riesgos químicos más serios en muchas ciudades es la contaminación del aire adentro de las casas por humo o emisiones de fogatas o estufas ineficientes (oMs, 1992). Esto ocurre especialmente cuando se usa carbón o alguna biomasa como combustible doméstico. Los niveles elevados de contaminación interior del aire pueden causar inflamación de las vías respiratorias, lo cual, a su vez, reduce la resistencia ante infecciones respiratorias agudas, y éstas aumentan nuevamente la susceptibilidad ante los efectos inflamatorios del humo y emisiones. Hay muchos otros problemas de salud asociados con los altos niveles de contaminación del aire en interiores (OMs, 1992).

También es necesario reducir al mínimo el riesgo de accidentes dentro de la casa y su entorno inmediato. Los accidentes domésticos suelen estar entre las causas más serias de lesiones y muerte prematura, especialmente en las ciudades del sur, donde es común que una elevada proporción de la población viva hacinada, con tres o cuatro personas por habitación en viviendas construidas con materiales temporales (e inflamables), usando fogatas o estufas para cocinar y como calefacción (donde es necesario). En estas circunstancias es casi imposible proteger de las quemaduras a los habitantes, especialmente a los más pequeños.

En el sur también hay decenas de millones de habitantes urbanos con riesgos de inundaciones o avalanchas de tierra o lodo. En la mayoría de sus ciudades una considerable proporción de la población vive en terrenos sujetos a inundaciones, avalanchas de lodo y desprendimiento de rocas. Las familias de bajos recursos escogen sitios tan riesgosos porque con frecuencia son los únicos lugares a los que tienen acceso cerca de las fuentes de empleo. Los sitios más seguros son muy caros y cualquier intento de ocuparlos ilegalmente para construir viviendas acabaría en un desalojo.

$\mathrm{Al}$ igual que en el control de enfermedades infecciosas y parasitarias, es necesario un buen sistema de salud básica y de servicios de emergencia, para que quienes se lesionen o intoxiquen puedan recibir un tratamiento adecuado. También es necesario un manejo del 
tránsito que minimice el riesgo de accidentes vehiculares y que prote:ja a los peatones, así como es necesario asegurar instalaciones adecuadas para el.juego y recreación de toda la población urbana. Se necesitan parques limpios, seguros y estimulantes para los niños, y sobre todo en las áreas residenciales más pobres, donde hay menos espacio dentro y alrededor de las casas para que los niños jueguen. En todas partes de la ciudad hay una necesidad urgente de un conjunto completo de medidas para promover prácticas laborales seguras y saludables en todos los tipos de empleo y para castigar a los patrones que las contravengan.

También es necesario controlar la contaminación del aire y agua. A medida que las ciudades crecen, se industrializan y se enriquecen, aparece una creciente necesidad de un control más completo y eficiente de las emisiones y desperdicios de las industrias y vehículos motorizados. A nivel mundial, más de 1500 millones de habitantes urbanos están expuestos a niveles de contaminación del aire superiores a los niveles máximos recomendados, y se estima que al año unas 400000 muertes adicionales se pueden atribuir a la contaminación del aire (oms, 1996). Una vez que se reducen en gran medida los problemas de contaminación del aire adentro de las casas, con el uso de combustibles más limpios, mejores estufas y mejor ventilación, y que los riesgos en el trabajo se reducen con el establecimiento efectivo de regulaciones de salud y seguridad, los gobiernos generalmente tienen que pasar su atención a disminuir la contaminación del aire exterior. Si bien la contaminación por fuentes industriales se ha reducido bastante, los vehículos motorizados suelen convertirse en la principal fuente de contaminación del aire urbano.

\section{Lograr un ambiente urbano de alta calidad}

Las acciones de las dos categorías anteriores se realizan esencialmente para reducir o eliminar los problemas de salud que surgen de la concentración de personas, empresas y sistemas de transporte motorizado en las ciudades. Se centran en la prevención y tratamiento rápido y efectivo de cualquier enfermedad o lesión. Esta tercera categoría difiere cualitativamente, en el sentido de que su meta es asegurar el suministro de aquellos servicios e instalaciones que hacen a una ciudad más agradable, segura y valorada por sus habitantes. Incluye asegurar cantidad y calidad suficientes de espacios al aire libre por persona 
(como jardines públicos, parques, instalaciones deportivas y recreativas), buscando que todos los habitantes de la ciudad tengan acceso a ellos. Integrado a esto debería haber un interés por proteger los paisajes naturales con valor ecológico y/o estético -como los humedales, las riberas de los ríos y las costas- y la herencia cultural de la ciudad. Hay vínculos obvios entre esto y las primeras dos categorías. Por ejemplo, si se aseguran en cada colonia de la ciudad instalaciones adecuadas de:juegos infantiles que sean seguros, bien cuidados, accesibles y administrados de manera que satisfagan las necesidades de grupos de distintos niveles de ingreso y de distintas edades, se pueden reducir bastante los accidentes, pues menos niños juegan en las calles, basureros o zonas peligrosas. Estas instalaciones también pueden contribuir mucho al desarrollo fisico, mental y social de los niños (Hart, 1997). Dichas instalaciones son particularmente importantes en las zonas más pobres de las ciudades del sur, que carecen de un suministro adecuado de agua, saneamiento y drenaje y donde las viviendas suelen estar abarrotadas, pues permiten que los niñosjueguen sin exponerse al riesgo de contaminación fecal o infección por basura o vectores (Satterthwaite, Hart, Levy et al., 1996).

También hay muchas otras formas de combinar el mejoramien to del ambiente urbano con la reducción de los riesgos ambientales. Por ejemplo, el cuidado de cuerpos de agua en los parques y de los humedales puede integrarse a los sistemas para tratar el agua de lluvia y para reducir el riesgo ante las inundaciones o limitar los daños cuando éstas ocurran. Sembrar árboles en las ciudades y suburbios se justifica no sólo por su valor estético, sino también por su contribución, entre otras cosas, a la reducción de los costos del aire acondicionado, absorción de contaminantes y efecto de rompevientos y barreras de sonido. El apoyo a la agricultura urbana puede integrarse al suministro de espacios al aire libre y al reciclaje de aguas residuales -y puede ser particularmente importante para mejorar la alimentación y bienestar de los grupos de bajos ingresos en la mayoría de los centros urbanos del sur (Smit et al., 1996).

Asegurar la provisión de espacios públicos en cada colonia, en formas que respondan a las distintas necesidades y prioridades de los diferentes grupos de la población, rara vez recibe atención en las ciudades de crecimiento rápido del sur. En consecuencia, en el tejido urbano se incluye poca o ninguna consideración de espacios públicos, y a medida que todos los terrenos se desarrollan con actividades urbanas, se vuelve casi imposible remediar esta deficiencia. Además, la presión de los grupos de ingreso medio y alto para que la acción pública aborde estas cuestiones puede disminuir a medida que su poder 
de compra les permite un acceso exclusivo a tales recursos -mediante la compra o renta de casas con jardines o casas en zonas con buena disposición de espacios abiertos, o la pertenencia a clubes que permiten a sus miembros el acceso a espacios abiertos, playas o instalaciones deportivas. La capacidad de las clases media y alta para pagar tales servicios puede no sólo reducir la presión de esos grupos para exigir una mayor disposición de espacios públicos, sino también provocar que los clubes campestres y deportivos, los campos de golf y las playas privadas obtengan un derecho preferencial sobre terrenos y recursos naturales que antes habían estado abiertos a todos los habitantes de la ciudad.

Minimizar la transferencia de costos ambientales a los habitantes y ecosistemas que rodean a la ciudad

Las categorías cuarta y quinta de acción ambiental se refieren ambas a minimizar la transferencia de costos ambientales a los ecosistemas y personas que se encuentran afuera de la ciudad. La cuarta categoría se concentra en la transferencia de costos a la región urbana, mientras que la quinta se concentra en la transferencia hacia personas y ecosistemas más distantes (incluyendo los de otras naciones) y hacia el futuro. La distinción entre estas dos es importante ya que un mejor desempeño en la primera comúnmente se logra a expensas de la segunda.

Las condiciones ecológicas de las regiones que rodean a las ciudades grandes y prósperas en general cambia mucho por la concentración en las ciudades de demanda de recursos y generación de residuos. Como ha descrito Ian Douglas, el desarrollo de las ciudades transforma los rasgos ecológicos de su región a medida que se da nueva forma a las superficies terrestres, se rellenan valles y pantanos, se extraen grandes volúmenes de arcilla, arena, grava y piedra triturada, se vacían las fuentes de agua y se canalizan los ríos y arroyos (Douglas, 1983, 1986). Este rearreglo de agua, materiales y exigencias a la superficie terrestre, combinado con la tendencia natural de los habitantes y empresas de las ciudades a disponer de sus residuos en la región que rodea a la ciudad, acarrea consecuencias dañinas. Los cambios provocados al ciclo hidrológico por las construcciones urbanas y los sistemas de agua entubada, saneamiento y drenaje generalmente producen consecuencias dañinas "río abajo". Además, a medida que se dispone de mejores alcantarillas y drenajes en la ciudad, aumenta el impacto de las aguas residuales en la 
región, pues se dispone de ellas sin tratamiento en los ríos, estuarios y mares cercanos. Con frecuencia se utilizan los desechos sólidos (incluyendo residuos tóxicos y peligrosos) en terrenos alrededor de la ciudad, por lo regular con poca o ninguna precaución para impedir que contaminen las fuentes de agua locales. La contaminación del aire por industrias urbanas, calefacción, estaciones de energía termal y vehículos motorizados resulta en precipitaciones ácidas que dañan los ecosistemas terrestres y acuáticos fuera de la ciudad. Las altas chimeneas de las plantas de energía termal y de las empresas urbanas también pueden simplemente transferir los costos ambientales de dentro y alrededor de la planta o empresa hacia otras zonas "viento abajo", aunque el impacto puede ser llevado mucho más allá de la región cercana a la ciudad. También está el daño a la vegetación producido por el ozono generado en las complejas reacciones fotoquímicas entre los contaminantes del aire urbano y la luz solar -las concentraciones de ozono suelen ser más altas "viento abajo" de las ciudades grandes y ricas que sobre las ciudades mismas (Conway y Pretty, 1991).

Fue apenas en los años sesenta que este aspecto del impacto ambiental de las ciudades comenzó a tratarse en el norte. El crecimiento del ambientalismo de los sesenta en adelante exigió mayores reducciones en la contaminación del aire, grandes inversiones en el tratamiento de desechos líquidos y en el manejo de los sólidos (con medidas especiales para los residuos peligrosos) y mayor control de la extracción de materiales de construcción en los alrededores de las ciudades. En las naciones más ricas del mundo esto ha reducido considerablemente el impacto ambiental de la producción urbana y del consumo en la región circundante. También se han comenzado a establecer límites al impacto ambiental que la demanda urbana de agua dulce puede infligir en las cuencas locales e incluso cada vez más distantes. Sin embargo, en la mayoría de las grandes ciudades del sur, queda mucho por hacer para aminorar la transferencia de costos ambientales a la región que rodea a la ciudad. Además, por lo menos parte de este problema ha sido solucionado transfiriendo los costos ambientales a gente y ecosistemas más lejanos.

\section{Consumo sustentable}

La quinta categoría de acción ambiental en cualquier ciudad es reducir o eliminar la transferencia de costos ambientales a personas y eco- 
sistemas que están más allá de la región urbana, incluyendo su transferencia hacia el futuro. Esto podría considerarse como asegurar que el desempeño ambiental de las personas y empresas en las que se concentra la ciudad se vuelva compatible con las metas del desarrollo sustentable en los niveles nacional y global.

Para las ciudades más grandes y más ricas, una gran parte de los costos ambientales que se transferían a la región vecina ahora se transfieren a otras regiones o a sistemas globales. Sus demandas concentradas de alimento, combustible y materias primas son satisfechas en gran medida con importaciones de ecosistemas distantes, de modo que se exige mucho menos a la región circundante -por lo cual es más fácil mantener altos criterios ambientales en esta región y, por ejemplo, conservar los bosques y paisajes naturales. Además, se pueden importar aquellos bienes cuya producción requiere un alto consumo de combustibles fósiles, agua y otros recursos naturales, procesos industriales sucios (incluyendo la generación de residuos peligrosos) y condiciones peligrosas para la fuerza de trabajo. La posibilidad de que las empresas y consumidores importen tales bienes se acrecienta por los bajos precios del petróleo.

Otras transferencias de costos son hacia el futuro. Por ejemplo, la contaminación del aire pudo haberse reducido en muchas de las ciudades más ricas del mundo, pero las emisiones de dióxido de carbono (el principal gas de invernadero) siguen siendo muy altas y en la mayoría de las ciudades siguen aumentando a causa, por ejemplo, de la creciente posesión y uso de automóviles particulares. Esto significa la transferencia de los costos hacia el futuro por medio de los costos ecológicos y humanos del calentamiento atmosférico. También se transfieren costos hacia el futuro al generar residuos peligrosos no biodegradables (incluyendo desechos radioactivos) o desechos no biodegradables cuyas concentraciones crecientes en la biósfera están produciendo consecuencias ecológicas preocupantes. También son transferencias de costos los niveles actuales de consumo de productos agrícolas y forestales procedentes de sitios donde se están degradando los suelos y bosques y donde se está reduciendo la biodiversidad.

Si bien hay desacuerdo en cuanto a los límites del uso de recursos no renovables, de la explotación de suelos y bosques y del uso de depósitos globales para verter gases de invernadero, está claro que los niveles de residuos y gases por persona generados con los estilos de vida de la mayoría de las familias de clase media o alta del norte no podrían mantenerse si la mayor parte de la población mundial tuviera 
niveles comparables. Quizá las familias ricas del sur tengan niveles de consumo semejantes a las del norte. No obstante, la capacidad de consumo y el impacto ambiental de estas últimas no sólo es mayor en la actualidad, sino que lo ha sido históricamente. Es este hecho lo que les da a los problemas ambientales globales su carácter de contradicción norte-sur.

Cuando se juzgan sólo en términos de uso de recursos y generación de desperdicios, la mayoría de los centros urbanos de los países más pobres del sur tiene un buen desempeño para que los bajos niveles de actividad económica y los limitados niveles de consumo en la mayor parte de la población aseguren que los índices de uso de recursos por persona sean muy bajos. También lo son los niveles per cápita de emisiones de gases de invernadero y de emisiones químicas destructoras del ozono estratosférico. Los ciudadanos de bajos ingresos también son modelos de consumo sustentable, ya que usan muy pocos recursos no renovables y generan muy pocos desperdicios. También están entre los más asiduos recolectores y utilizadores de materiales reciclados o de escombro. Pero ésta es también la gente que enfrenta la pobreza más severa y que tiene los problemas ambientales más serios en términos de exposición a enfermedades infecciosas y parasitarias y a riesgos químicos y físicos. Esto es un recordatorio de la necesidad de evaluar el desempeño ambiental de las ciudades en las cinco categorías mencionadas.

\section{Evaluar las huellas humanas y ecológicas de las ciudades, tanto regionales como globales}

Es difícil estimar los costos ambientales que provoca la producción del amplio y variado rango de materias primas, bienes intermedios y bienes finales que cubren las demandas de los productores y consumidores urbanos. Ciertos conceptos han ayudado a visualizar y comenzar a cuantificar la escala y carácter de estas transferencias interregionaies e internacionales de los costos ambientales. Uno de ellos es el cálculo de la huella ecológica de las ciudades, desarrollado por William Rees (Rees, 1992; Wackernagel y Rees, 1996), que evidencia la gran área territorial de cuya producción dependen los habitantes y empresas de cualquier ciudad, en términos de alimento, otros recursos renovables y absorción de carbono para compensar el dióxido de carbono emitido por el uso de los combustibles fósiles. Rees 
calculó que la parte baja del valle de Fraser en British Columbia (Canadá), donde está ubicada Vancouver, tiene una huella ecológica unas 20 veces mayor que el área que ocupa -para producir los productos alimenticios que usan sus habitantes y empresas y la vegetación necesaria para absorber el dióxido de carbono que producen (Rees, 1992). A partir de criterios semejantes se estimó que la huella ecológica de Londres tiene aproximadamente 152 veces el tamano de la ciudad (Jopling y Giradet, 1996). Sin embargo, hay que tener cuidado al comparar el tamaño de las huellas ecológicas de distintas ciudades. Una razón es que el tamaño de la huella como múltiplo del área de la ciudad puede variar considerablemente dependiendo del punto en que se tracen los límites de la ciudad -ésta es la principal razón por la cual los habitantes de Londres parecen tener una huella ecológica individual mucho mayor que la de los habitantes del valle de Fraser. ${ }^{2}$ Una segunda razón son las diferencias entre ciudades en cuanto a la calidad y rango de las estadísticas con las cuales se calcula la huella ecológica. Finalmente, el cálculo de las huellas ecológicas de las ciudades no debe oscurecer el hecho de que empresas particulares y los grupos económicos más ricos contribuyen de manera desproporcionada a estas huellas. Por ejemplo, Wackernagel y Rees (1996) calcularon que la huella ecológica promedio para el $20 \%$ más pobre de la población canadiense corresponde a menos de la cuarta parte de la huella promedio del $20 \%$ más rico.

El concepto de huella ecológica también puede aplicarse a actividades particulares -por ejemplo, Wackernagel y Rees (1996) consideran la huella de distintos tipos de vivienda, patrones comunitarios, puentes carreteros y de distintos bienes (incluyendo la producción de tomate y de periódicos). Otro concepto que ayuda a revelar la dependencia de las ciudades ricas en cuanto a recursos no renovables es el cálculo de la intensidad material de los bienes consumidos en cada ciudad (lo que a veces se llama la carga ecológica de esos bienes). La intensidad material de cualquier bien puede calcularse, en relación con el servicio que proporciona, como una estimación rápida y burda de su impacto ambiental (Schmidt-Bleek, 1993). Este

\footnotetext{
${ }^{2}$ El cálculo para Londres se basó en un área de $1580 \mathrm{~km}^{2}$ (prácticamente todo lo cual es área construida) y una población de 7 millones. Los cálculos para la parte baja del valle de Fraser correspondieron a una región urbano-agricola de $4000 \mathrm{~km}^{2}$ y una población de 1.8 millones de habitantes.
} 
cálculo puede incluir todos los insumos materiales y energéticos invertidos en un bien determinado, desde la extracción o elaboración de los materiales usados para producirlo, pasando por su utilización, hasta su disposición final. También puede incluir consideraciones de cuán to servicio ofrece ese bien, incluyendo cuánto dura -así, un refrigerador o un automóvil que dura 20 años tendría una menor intensidad material que uno que dura 10 años. Se ha calculado que un refrigerador doméstico diseñado para reducir su razón "insumo material: intensidad de servicio" podría construirse con la tecnología y materiales disponibles de modo que lograra una productividad por recurso de aproximadamente seis veces más que la de los modelos disponibles en la actualidad (Tischner y Schmidt-Bleek, 1993). También está la antigua práctica de calcular la intensidad energética de distintos bienes, que puede tomar en cuenta la energía invertida en su fabricación, transporte, preparación para la venta, venta, utilización y disposición. Como en la mayoría de los casos casi todos o todos los insumos energéticos provienen de combustibles fósiles, esto ofrece una idea de cómo el uso de determinado bien contribuye al uso de combustibles fósiles y a la generación de dióxido de carbono (el principal contribuyente al calentamiento atmosférico) -y quizás también ofrezca cierta idea de lo que implica para la contaminación del aire su elaboración, uso y disposición.

Si bien estos conceptos han ayudado a evidenciar el grado al que las ciudades modernas generan costos ambientales lejos de sus límites, sigue siendo difícil cuantificar todas esas transferencias. Por ejemplo, se desconocen las consecuencias de salud y las ecológicas en el largo plazo de muchos desechos químicos, incluyendo los que surgen de la acumulación de ciertos químicos persistentes. También es difícil estimar la escala de riesgos a la salud que enfrentan los trabajadores (y sus familias) que producen los bienes que usan los consumidores y empresas en las ciudades ricas. Igualmente, es difícil ajustar los cálculos para que la huella ecológica de una ciudad tome en cuenta los bienes y servicios que sus empresas ofrecen a los que viven fuera de sus límites. Por citar un ejemplo extremo, una ciudad que produce celdas solares o autobuses de bajo consumo energético tendría que considerar en su huella ecológica los insumos de combustibles fósiles necesarios para producir esos bienes, pero no se consideraría en el cálculo la contribución de dichos bienes a la reducción de la huella ecológica de otras localidades. 


\section{Restricciones a la acción en las cinco categorías}

La distinción entre las cinco categorías de acción ambiental esbozadas se refleja en la evolución histórica de las intervenciones gubernamentales en el ambiente urbano: la primera categoría se volvió una preocupación central durante la segunda mitad del siglo xix (que suele llamarse la revolución sanitaria) y la segunda y tercera le siguieron poco después, aunque el progreso en muchos de sus aspectos tuvo que esperar hasta que la presión ciudadana ayudara a asegurar que el cuidado de la calidad ambiental se volviera una parte aceptada de las responsabilidades del gobierno. La cuarta y quinta categorías son más recientes en términos de su discusión generalizada entre los gobiernos y agencias internacionales, aunque por lo menos desde hace $\mathbf{2 0}$ años existe bibliografía especializada acerca de la necesidad de avanzar en esa dirección (véase por ejemplo Ward, 1976 y las discusiones sobre una "sociedad conservadora" en Canadá a mediados de los setenta). ${ }^{3}$ No debe considerarse que esto implica que la acción ambiental en las ciudades debe pasar por estas cinco categorías de manera secuencial -y en verdad ofrece muchas ventajas en el largo plazo que los gobiernos reconozcan la validez de las cinco, mientras sus prioridades no se distorsionen (como cuando un interés por el consumo sustentable provoca un alejamiento de las necesidades más urgentes e inmediatas de una salud ambiental mejorada).

La distinción entre las cinco categorías también es útil al considerar la economía política de los problemas ambientales, pues hay diferencias entre las categorías en términos de quién es responsable de los problemas, a quién le afectan más, las posibilidades de los afectados de enfrentarlos, cómo se enfrentan y quién lo hace. Abordar los problemas ambientales de la primera categoría se ha considerado desde hace mucho responsabilidad de las autoridades públicas -en salud pública y ambiental- inclúso si muchas de las acciones pueden ser delegadas o concedidas a empresas privadas, organizaciones no gubernamentales (ONG) u organizaciones comunitarias. En la segunda categoría se reconoce nuevamente como el papel de las autoridades públicas establecer criterios y aplicarlos $-\mathrm{y}$ los sindicatos y otras organizaciones de trabajadores tienen un papel importante en la pro-

${ }^{3}$ Éstas aparecieron en la publicación trimestral Conserver Society Notes del Consejo de Ciencia de Canadá, en Ottawa. 
moción de soluciones para la salud y seguridad laborales, mientras que los grupos de consumidores y estructuras políticas democráticas son importantes para actuar respecto a otros riesgos químicos y físicos. Las estructuras políticas democráticas también son de gran importancia en la tercera categoría, para asegurar que se aborden las prioridades ambientales de todas las poblaciones de la ciudad.

Hay intereses personales evidentes que se oponen a la acción pública en cada una de estas categorías, pues implican ya sea costos más altos para ciertas compañías o ciudadanos, o controles sobre lo que pueden hacer en sus empresas, en las tierras que adquieren o con los desperdicios que generan. Pero en las primeras tres categorías las autoridades urbanas por lo menos pueden buscar acuerdos entre los implicados, y es una de sus funciones centrales hacerlo. En la mayoría de las ciudades hay áreas de amplio acuerdo entre los diversos grupos en cuanto a la promoción de salud, prevención de enfermedades y logro de la calidad ambiental -y el desarrollo y promoción de esta agenda común es el núcleo de los programas de ciudades saludables (oMs, 1996).

Una importante dificultad institucional surge cuando los problemas o costos ambientales se están transfiriendo de un área a otra y la estructura de las autoridades locales está formada por autoridades diferentes y en gran medida autónomas, sin mecanismos para abordar las disputas y transferencias de recursos entre municipios. La transferencia de costos ambientales de las áreas más ricas a las más pobres al interior de los países o regiones subyace en lo que suele llamarse "racismo ambiental", como en el hecho de que las industrias o residuos contaminantes se colocan sistemáticamente en zonas de bajos ingresos. También está la dificultad institucional de abordar los problemas ambientales de la cuarta categoría, pues las autoridades de la ciudad no tienen:jurisdicción en la región circundante más amplia y el poder de los intereses personales urbanos en cuanto al uso de los recursos o depósitos vecinos en formas ecológicamente dañinas suele ser mayor que el poder de los habitantes.

Las dificultades institucionales de las primeras cuatro categorías tienen mayores posibilidades de resolverse, pues por lo menos caen dentro de los límites de una misma nación. Para la quinta categoría no sucede así y es dificil prever la manera de prevenir este tipo de transferencia. Ha habido algún progreso en este ámbito en años recientes, sobre todo mediante la presión ejercida sobre los gobiernos y empresas por parte de los grupos de consumidores y las ong (véase entre otros Harrison, 1997). Por ejemplo, lo que se llama "consumo 
verde" -donde los compradores eligen bienes cuya elaboración o uso tienen menos consecuencias ambientalmente dañinas, con el apoyo de un "eco-etiquetado" hecho por grupos ambientalistas- ha presionado a muchos fabricantes para que consideren las implicaciones ambientales de la elaboración, uso y disposición de sus productos. Las campañas de "comercio:justo" y la venta de "bienes comerciales :justos" han ayudado a plantear cuestiones como los salarios y/o condiciones laborales de aquellos que fabrican los bienes, o los historiales de derechos humanos de sus gobiernos. También se ha presionado a los productores o vendedores para que tomen más en serio lo que se llama "ética de proovedores" - por ejemplo, evitar el uso de bienes producidos en países o compañías con malos historiales ambientales o de derechos humanos. Las inversiones o productos "antiéticos" o el pobre desempeño ambiental de muchas compañías han sido expuestos con campañas -como las que promueven los boicots de consumidores a los productos de esas compañías- o cuando los activistas ambientales o de derechos humanos compran acciones y presionan a la compañía en las reuniones de accionistas. Hay ejemplos de compañías (incluyendo corporaciones multinacionales) que se han comprometido explícitamente a mejorar su desempeño ambiental o mejorar los salarios y condiciones laborales de su fuerza de trabajo o de aquellos que trabajan en las principales filiales -algunas incluso permiten auditorías independientes de sus instalaciones. Hay ejemplos de gobiernos que han promovido o apoyado el "eco-etiquetado" y el control de ciertas importaciones por razones éticas o ambientales. Pero las personas afcctadas por la transfcreneia internacional de costos ambientales no tienen una influencia política directa sobre los gobiernos de las naciones que importan los bienes que ellas ayudaron a fabricar.

Hay cierta acción internacional para ayudar a prevenir algunas de las transferencias más obvias y descaradas de costos ambientales, como al controlar la exportación de residuos peligrosos y el tráfico de especies amenazadas o de productos derivados de ellas. Pero se amenazarían los fundamentos del comercio internacional si la acción se extendiera para ocuparse de todas estas transferencias -por ejemplo, si los gobiernos del norte sólo permitieran la importación de productos de países del sur donde se cumplieran altos criterios de salud y seguridad laborales, o si la importación de bienes producidos en corporaciones multinacionales sólo se permitiera si la corporación y sus principales filiales cumplieran con criterios acordados de una buena 
práctica ambiental en el uso de recursos y generación y manejo de desperdicios en todas sus operaciones en distintos países (permitiendo el monitoreo de sus operaciones por parte de grupos independientes). Estos controles parecen oponerse al proceso de globalización, pero es difícil prever la forma de prevenir la transferencia de costos ambientales a otras personas o ecosistemas sin tales medidas (Goodland, 1995, y Redclift, 1996). Las iniciativas para promover el "consumo verde" y el "comercio:justo" sólo pueden tener un efecto limitado si los bienes que promueven tienen que competir con aquellos cuyo precio menor refleja los salarios inadecuados o las malas condiciones laborales de quienes los produjeron, o la evasión de gastos por medio del descuido del control de contaminantes o del mane:jo de residuos.

Integrar el desempeño ambiental mejorado a las metas sociales, económicas y políticas del desarrollo sustentable

Una de las cuestiones más debatidas en la discusión sobre el desarrollo sustentable es a qué se refiere sustentable. Una revisión de la bibliografia al respecto encontró que la mayor parte se ocupa casi exclusivamente de la sustentabilidad ecológica, con poca o ninguna mención del "desarrollo" en el sentido de satisfacción de necesidades humanas (Mitlin, 1992). Quizás en parte como reacción ante esto, también hay discusiones sobre desarrollo sustentable que se enfocan de manera casi exclusiva en la satisfacción de necesidades humanas, con poca consideración por la sustentabilidad ecológica -como en los documentos de Hábitat II, como se verá más adelante. Hay aún un tercer conjunto de bibliografia, en su mayoría procedente de agencias internacionales, donde el término "desarrollo sustentable" se usa en discusiones sobre si los proyectos de dichas agencias continuarán funcionando después de que se retire la ayuda extranjera; aquí también se da poca o nula consideración a la sustentabilidad ecológica. Quizá lo que hace tan importante la declaración de la Comisión Brundtland es su insistencia en que la satisfacción de las necesidades humanas debe combinarse con la sustentabilidad ecológica, para satisfacer "las necesidades del presente sin comprometer la capacidad de las generaciones futuras para satisfacer sus propias necesidades" (Comisión Mundial para el Medio Ambiente y el Desarrollo, 1987: 8). 
En un trabajo previo con Jorge Hardoy y Diana Mitlin sugerimos que lo sustentable del desarrollo sustentable se considera como el hecho de evitar el agotamiento del capital ambiental (es decir, concentrarse en la sustentabilidad ecológica), mientras que el desarrollo se considera como la satisfacción de las necesidades humanas (véase por ejemplo Hardoy, Mitlin y Satterthwaite, 1992; Mitlin y Satterthwaite, 1996). Esto llevó a una elaboración de las metas sociales, económicas y políticas, a partir de la mencionada declaración de la Comisión Brundtland -dentro de un compromiso para limitar o detener el agotamiento de los cuatro tipos de capital ambiental (cuadro 1). La parte superior de este cuadro resume las metas sociales, económicas y politicas inherentes a la satisfacción de las necesidades humanas, que no se elaborarán aquí porque el propósito de este artículo es concentrarse en los aspectos ambientales del desarrollo sustentable. ${ }^{4}$

\section{CUADRO 1}

Las múltiples metas del desarrollo sustentable aplicado a las ciudades

\section{Satisfacer las necesidades del presente...}

- Necesidades económicas: incluyen acceso a un bienestar adecuado o a medios de producción, así como seguridad económica en el desempleo, enfermedad, incapacidad $u$ otra imposibilidad de asegurar el bienestar.

- Necesidades sociales, culturales y de salud: incluye una vivienda segura, saludable y accesible, en una colonia con suministro de agua potable, drenaje, saneamiento, transporte, servicios de salud, educación y desarrollo infantil. También un hogar, lugar de trabajo y ambiente general protegidos de riesgos ambientales, incluyendo contaminación química. También son importantes las necesidades relacionadas con la posibilidad de elección y control por parte de las personas -incluyendo casas y colonias valoradas y donde se satisfagan sus prioridades sociales y culturales. Las viviendas y servicios deben cumplir con las necesidades específicas de los niños y de los adultos responsables de su crianza (en general mujeres). Lograr esto implica una distribución más equitativa del ingreso entre las naciones y, sobre todo, dentro de las naciones.

- Necesidades políticas: incluyen la libertad de participar en la política nacional y local y en las decisiones referentes al manejo y desarrollo de la propia casa y colonia -dentro de un marco más amplio que asegure el respeto de los derechos civiles y políticos y el establecimiento de una legislación ambiental.

${ }^{4}$ Los aspectos sociales, económicos y políticos se describen con mayor detalle en Mitlin y Satterthwaite, 1996. 
CUADRO 1(continuación)

Desarrollo sustentable y ciudades

...sin comprometer la capacidad de las generaciones futuras de satisfacer sus propias necesidades

- Minimizar el uso y desecho de recursos no renovables. incluye minimizar el consumo de combustibles fósiles en la casa, comercio, industria y transporte, además de sustituirlos por fuentes renovables cuando sea factible. También minimizar el desperdicio de recursos minerales escasos (reducir el uso, reutilizar, reciclar y regenerar). En las ciudades también hay bienes culturales, históricos y naturales que son irremplazables y, por lo tanto, no renovables -como los parques y distritos históricos y los paisajes naturales que ofrecen espacios para.jugar y para la recreación y acceso a la naturaleza.

- Uso sustentable de los recursos renovables'finitos: extraer agua dulce a niveles que se puedan sostener (promoviendo el reciclaje y reutilización). Mantener una huella ecológica sustentable en términos del área territorial aprovechada por los productores y consumidores urbanos para obtener productos agrícolas y forestales y combustibles de biomasa.

- No sobrecargar los depósitos renovables con residuos biodegradables: los depósitos renovables se refieren por ejemplo a la capacidad de un río para descomponer residuos biodegradables sin degradación ecológica.

- No sobrecargar la capacidad (finita) de los depósitos locales y globales para absorber o diluir los residuos/emisiones no biodegradables sin efectos adversos: éstos son, por ejemplo, los pesticidas persistentes, gases de invernadero y químicos destructores del ozono estratosférico.

Fuente: Elaborado a partir de Midin, Diana, y David Satterthwaite, Cities and Sustainable Development, artículo para el Foro Mundial 1994 (Global Forum 1994), Manchester City Council/mED, junio de 1994.

Sin embargo, debe mencionarse la cuestión del crecimiento poblacional, ya que afecta tanto al componente sustentable como al de desarrollo -y que rara vez recibe atención dentro de las discusiones sobre desarrollo sustentable y ciudades (Drakakis-Smith, 1996). Discutir el crecimien to poblacional es complicado por la escala de diferencias entre los consumidores mayores y menores en cuanto a su contribución al agotamiento del capital natural. Hay una tendencia a asumir que el tamaño de la población de un país, ciudad o región es la principal influencia sobre su agotamiento del capital natural, y que la tasa de crecimiento poblacional es la principal influencia sobre la tasa de 
cambio en este agotamiento. Pero una proporción significativa de la población urbana del sur (incluyendo mucha de la gente de ciudades que han tenido tasas de rápido crecimiento poblacional en las últimas décadas) tiene niveles de consumo que son tan bajos que contribuyen poco o nada al uso de recursos no renovables y a la generación de residuos, incluyendo la generación de gases de invernadero. En el nivel mundial, la mayor parte del uso de recursos y de la generación de desperdicios proviene de los patrones de consumo de las familias de clase media y alta (la mayoría con tasas de fecundidad muy bajas) y de las empresas que producen los bienes que éstas consumen. Además, los países del sur que en las últimas décadas han tenido las economías de crecimiento más rápido también suelen ser los que han tenido el aumento más rápido en el uso del capital natural y en general las mayores disminuciones en el crecimiento poblacional. ${ }^{5}$ En cuanto al desarrollo sustentable, quizás la cuestión que es más importante remarcar es que satisfacer las necesidades humanas como se esboza en el cuadro 1, lo cual incluye la satisfacción de las necesidades de salud sexual y reproductiva de hombres y mujeres, también favorece una rápida disminución en las tasas de fecundidad en países con altas tasas de crecimien to poblacional (véase por ejemplo Sen, Germain y Chen, 1994). Sin embargo, también puede ofrecer la base para que mucha más gente escoja estilos de vida altamente consumistas, que es la razón por la que la satisfacción de las necesidades humanas debe combinarse con consideraciones sobre cómo reducir el agotamiento del capital ambiental.

Esta distinción entre los componentes de sustentabilidad ecológica y desarrollo en el desarrollo sustentable tiene la ventaja de evitar las ambigüedades inherentes a términos como sustentabilidad económica, sustentabilidad socialy sustentabilidad cultural, donde no queda claro qué es lo que se va a sostener y cómo el hecho de sostenerlo afectaría al capital ambiental. Por ejemplo, el concepto de sustentabilidad social podría entenderse como el mantenimiento de las sociedades actuales y de sus estructuras sociales, mientras que la satisfacción de necesida-

${ }^{5}$ Esta asociación oscurece los muchos factores que influyen en la fecundidad. También oscurece el hecho de que no es necesario tener ingresos per cápita altos o en rápido ascenso para tener tasas de crecimiento poblacional bajas o para disminuirlas como puede verse, por ajemplo, en el estado de Kerala, India, donde una alta prioridad a la educación y atención a la salud ayudaron a lograr bajas tasas de crecimiento poblacional con ingresos per cápita bajos y sin políticas coercitivas de control poblacional (Sen, 1994). Véase también Sen, Germain y Chen, 1994. 
des humanas sin agotar el capital natural implica cambios importantes en las estructuras sociales existentes. Si la sustentabilidad social se entiende como las medidas sociales necesarias para impedir la ruptura o conflicto sociales -justificando así la reducción de la pobreza-, como señalan McGranahan, Songsore y Kjellên (1996), entonces la objeción legítima a la pobreza no es que socava la "sustentabilidad social", como protestan los pobres, sino el sufrimiento que causa.

Frases como "ciudades sustentables", "asentamientos humanos sustentables" y "urbanización sustentable" también son poco claros por razones similares. ${ }^{6}$ Lo que busca sostener el desarrollo sustentable no son las ciudades o la urbanización, sino la satisfacción de las necesidades humanas en asentamientos de cualquier tamaño, sin agotar el capital natural. Esto significa buscar el marco institucional y regulativo dentro del cual las autoridades democráticas y administrativas de las ciudades y municipios aseguren que se abordarán las necesidades de las personas dentro de sus límites mientras se minimiza la transferencia de costos ambientales a otra gente o ecosistemas o hacia el futuro. Esto a su vez requiere considerar los tipos de políticas nacionales, marcos legales e institucionales y acuerdos internacionales que promoverán la orientación de las autoridades urbanas y municipales hacia ese objetivo.

Los marcos locales, nacionales e internacionales para promover el desarrollo sustentable en las ciudades

Al comienzo de este artículo se hicieron notar muchos ejemplos de progreso hacia las metas del desarrollo sustentable por parte de las autoridades urbanas y municipales de distintas regiones del mundo. Hay ejemplos de innovaciones de tales autoridades en las cinco categorías de acción ambiental descritas. Esto destaca la relevancia que para todas las ciudades tiene lo señalado por el reporte de la Comisión Europea sobre las ciudades europeas sustentables (Comisión Europea, 1994): que los gobiernos locales, con sus muchas y variadas funciones, están en posición de apoyar las metas del desarrollo sustentable, ya sea como proveedores directos o indirectos de servicios, reguladores, líderes, informantes comunitarios, defensores, conseje-

${ }^{6} \mathrm{La}$ justificación para evitarlas se discute con mayor detalle en Mitlin y Satterthwaite, 1996. 
ros, socios, movilizadores de recursos comunitarios o iniciadores de diálogos y debates. También hay ejemplos de cómo lo que podría denominarse una lógica de consumo sustentable puede institucionalizarse en códigos de construcción o zonificación, en las subdivisiones de la regulación, en la planificación de transporte, suministro de agua, disposición de aguas residuales, recreación y expansión urbana, en la generación de ingresos locales (mediante impuestos y cuotas ambientales) y en la inclusión de consideraciones ambientales en los presupuestos, compras y propuestas de las autoridades locales.

Pero también tienen límites las capacidades de acción de las autoridades urbanas y municipales. Esto es especialmente cierto en la mayor parte de África, Asia y Latinoamérica, donde los poderes y recursos a su disposición limitan severamente su capacidad de actuar en las cinco categorías descritas. Aunque durante los últimos diez o quince años en muchos países del sur ha habido cierta descentralización de la capacidad de toma de decisiones y un considerable progreso hacia autoridades urbanas más democráticas y transparentes, la mayoría de éstas tiene a su disposición recursos muy limitados para hacer inversiones de capital (UNCHs, 1996). Para esto dependen de autoridades gubernamentales superiores o de ayuda internacional para el desarrollo (negociada por medio de las autoridades gubernamentales superiores) y evidentemente es dificil desarrollar un programa a largo plazo para mejorar el desempeño ambiental sin una fuente segura de financiamiento. Privatizar los servicios públicos puede ser otra fuente de capital de inversión, aunque las empresas privadas en general sólo están interesadas en aquellos aspectos del mejoramiento ambiental por los cuales se puede cobrar a los beneficiarios. Además, en el sur se ha exagerado el grado en el cual la privatización puede compensar a las autoridades locales débiles e ineficaces (Sivaramakhrishnan, 1997). Irónicamente, aunque se concibió como una solución a autoridades urbanas débiles e ineficaces, la privatización suele operar mejor cuando las autoridades locales son capaces de establecer términos adecuados para las empresas del sector privado, vigilar los costos y calidad de los servicios que ofrecen y, cuando sea necesario, exigir el cumplimiento de los términos y precios acordados.

En el norte las autoridades locales generalmente tienen muchos más recursos, personal mejor capacitado y fuentes más seguras de capital de inversión, aunque las autoridades urbanas y municipales de las zonas urbanas más pobres enfrentan problemas particulares. Pero 
todas las autoridades urbanas y municipales están limitadas en cuanto a lo que pueden lograr en la quinta categoría, "consumo sustentable", aunque el desarrollo sustentable no puede lograrse si no se progresa en esta categoría. Las descripciones de experiencias recientes en ciudades europeas demuestran un amplio rango de innovaciones ambientales -como ampliar la "peatonalización" de las calles, modificar el transporte público y el manejo de los desechos (incluyendo reciclaje y disminución de los desechos) y "enverdecimiento" urbano (Comisión Europea, 1994; Mega, 1996a, 1996b). Se exhiben muchos ejemplos de buen gobierno, a medida que las autoridades urbanas se vuelven más explícitas en sus metas de mejorar la salud y el desempeno ambiental, más transparentes y cooperativas en sus formas de trabajar y más comprometidas ante las auditorías ambientales (ibid.). Sin embargo, mucho de lo que se está haciendo sólo tiene alcance local o regional, cubriendo así sólo las primeras cuatro categorías en las que es necesario actuar. Al mejorar el ambiente de cada ciudad, proteger su herencia cultural ( $y$ al hacerlo aumentar su atractivo para la inversión y el turismo) y reducir el daño ambiental que se hace a la región circundante, no se reducen necesariamente las emisiones de gases de invernadero (aunque algunas de las iniciativas sí lo hacen al reducir el uso de combustibles fósiles).

Esto implica la necesidad de acuerdos internacionales que establezcan límites exigibles a los recursos escasos (o recursos cuyo uso implica costos ecológicos inaceptables) que consume cada nación y al uso que hace cada una de los depósitos globales para disponer de sus desechos. Pero también está claro que la mayor parte de la acción para lograr el desarrollo sustentable tiene que formularse y llevarse a cabo en el nivel local. El hecho de que cada pueblo, provincia o ciudad sea único, así como es única su inserción en los ecosistemas locales y regionales, implica la necesidad de un uso óptimo de los recursos locales y conocimiento y habilidades para lograr las metas del desarrollo dentro de un conocimien to detallado de la capacidad de carga ecológica local y regional (véase por ejemplo Drakakis-Smith, 1996). Como señala Pugh:

En todos los niveles de la aplicación de políticas y programas (de las agencias del gobierno) hay complejidades situacionales al esforzarse por equilibrar la eficiencia económica, la operación de mercados, consideración de los intereses públicos y los aspectos de externalidad económica del ambiente, y atender cuestiones que afectan a la pobreza y.justicia social (Pugh, 1996: 234-235). 
Esto requiere un grado considerable de autodeterminación, pues las estructuras centralizadas dificilmente pueden tomar decisiones que respondan de manera apropiada a tal diversidad. No obstante, los marcos nacionales e internacionales son necesarios para asegurar que las ciudades o países individuales no se aprovechen de las restricciones de los otros. Las ciudades donde las empresas, consumidores y autoridades locales mejoran su desempeño ambiental, incluyendo una menor transferencia de costos ambientales a otras localidades, deben ser recompensadas, no penalizadas cuando las empresas y consumidores que quieren evitar un buen desempeño ambiental se mudan a otra parte.

Está el peligro que destaca Redclift (1996), de que la "solución" de lo que se percibe como problemas globales puedan ser formas de manejo ambiental global. Pero estos problemas globales son producto de la agregación de la producción y consumo, con una gran proporción concentrada en los centros urbanos del mundo. Redclift sugiere que no se puede "manejar" el ambiente de manera exitosa a nivel global si primero no se progresa hacia la sustentabilidad a nivel local: "De hecho, estamos inventando nuevas estructuras institucionales para manejar el ambiente que tienen poca o ninguna relación con los procesos mediante los cuales se está transformando el ambiente" (1996: 1). Pero también es difícil ver cómo las decisiones locales podrán incorporar responsabilidades globales sin acuerdos internacionales entre los gobiernos para comprometerse a abordar los pi ublemas globales dentro de sus fronteras. Si los gobiernos de las naciones del norte se comprometen a reducir los niveles de emisión de gases de invernadero, tendrán que desarrollar incentivos y regulaciones que apoyen la reducción de dichas emisiones en cada localidad -aunque con decisiones locales acerca de la mejor manera de lograrlo. Como señala también Redclift (1996), esto debe hacerse de manera que se incorpore al comportamiento mismo un conocimiento de las consecuencias de dicho comportamiento, en lugar de tratar de inventar técnicas de manejo para combatir las contradicciones del desarrollo. Es necesario recuperar el control del consumo, en lugar de establecer nuevas instituciones que se encarguen de sus consecuencias (Redclift, 1996).

Los gobiernos nacionales tienen la principal responsabilidad de asegurar que las autoridades locales cumplan las categorías cuatro y cinco, además de las primeras tres. En el nivel internacional tienen la responsabilidad de llegar a acuerdos que limiten la demanda de capi- 
tal ambiental mundial por parte de los consumidores y empresas de su país. Pero hay poca evidencia de que los gobiernos nacionales estén estableciendo una estructura de regulaciones e incentivos que asegure que el impacto agregado del consumo de sus ciudadanos y de las actividades económicas que ocurren al interior de sus fronteras no esté transfiriendo costos ambientales a otras naciones o hacia el futuro -aunque algunos gobiernos de Europa han dado pasos tentativos hacia ciertos aspectos (Comisión Europea, 1994; unchs, 1996; Mega, 1996b). Lo que también es notable es la poca atención que reciben las cuestiones urbanas en las estrategias nacionales de desarrollo sustentable, a pesar del papel prominente de la producción y consumo urbanos en la mayor parte del uso de recursos, generación de desechos y emisión de gases de invernadero del país, y a pesar del gran potencial de las ciudades y de las políticas urbanas para contribuir al consumo sustentable (Mitlin y Satterthwaite, 1996; uNchs, 1996). Gran parte de la literatura general sobre planes nacionales de medio ambiente y de desarrollo sustentable también ignora o presta muy poca atención a las cuestiones urbanas. ${ }^{7}$

El tipo de estructura regulativa y de incentivos necesaria para promover el logro de las metas del desarrollo sustentable en las ciudades es relativamente fácil de concebir, como ejercicio abstracto. Ciertamente, es posible satisfacer las necesidades humanas y reducir en gran medida la pobreza sin una expansión en el uso de recursos y en la generación de desechos, que amenazan la sustentabilidad ecológica. También es posible concebir una considerable reducción en el uso de recursos y generación de desechos entre las familias de clase media y alta sin disminuir su calidad de vida y en algunos casos incluso aumentándola (véanse los diversos estudios que muestran cómo en el norte se podría reducir de manera considerable el uso de combustibles fósiles sin disminuir los niveles de calidad de vida; por ejemplo Leach et al., 1979). El trabajo del Rocky Mountain Institute de Estados Unidos (entre otros grupos) ha destacado el grado al que es posible reducir el uso de recursos y generación de desechos en las economías prósperas sin comprometer los estándares de vida (véase por ejemplo Lovins y Lovins, 1991). Igualmente hay un considerable potencial para la creación de empleos al pasar a niveles más bajos de uso

7 Véase por ejemplo la falta de atención prestada a las cuestiones y políticas urbanas en Carew-Read et al., 1994, y Dalal-Clayton, 1996. 
de recursos y generación de desechos, aunque sufririan ciertos empleos en algunas empresas o sectores. ${ }^{8}$

Además, es posible concebir que las naciones más pobres logren la prosperidad y estabilidad económica que necesitan para asegurar el bienestar y condiciones de vida decentes para sus poblaciones, así como el necesario fortalecimiento de la competencia y responsabilidad de sus gobiernos, sin que aumente demasiado su demanda de capital ambiental. Existe conocimiento sobre cómo desarrollar de manera más productiva y sustentable la agricultura (véase por ejemplo Pretty et al., 1992), el manejo forestal (véase Sargent y Bass, 1992), la producción industrial (Robins y Trisoglio, 1992) y los patrones de asentamiento (Breheny, 1992; Haughton y Hunter, 1994; Blowers, 1993; uNCHs, 1996). Pero quedan mucho más inciertas las perspectivas para traducir lo posible en los marcos nacionales y acuerdos internacionales necesarios. Fuertes intereses personales se oponen a la mayoría, si no es que a todas, las políticas y prioridades necesarias. Los grupos más ricos se opondrán a lo que perciben como restricciones a su derecho de consumir o costos más elevados por los cambios en las estructuras de los precios para estimular la conservación y reducción de desechos. El cambio tecnológico puede ayudar a resolver esto -por ejemplo, moderando el efecto de los crecientes precios de la gasolina mediante la introducción relativamente rápida de automóviles más eficientes en el consumo de energía, y de combustibles alternativos derivados de fuentes de energía renovables. Pero si combatir el calentamiento atmosférico exige el nivel de reducción en las emisiones de gases de invernadero que sugiere la evaluación más reciente de la IPCc, se tendrían que hacer cambios en el derecho al uso particular del automóvil que no podrían ser compensados por las nuevas tecnologías y combustibles alternativos ("renovables") -por lo menos con costos que actualmente resultaran políticamente aceptables. Como comentó recientemente el profesor O'Riorden, “cuanto más se ha fortalecido el esfuerzo científico por frenar el calentamiento global, tanto más se han retirado los políticos" (Pearce, 1997: 12).

También están las dificultades para transformar los edificios, patrones de asentamiento y sistemas urbanos, de transporte y de disposición de desechos desarrollados durante los últimos 40 años de precios

${ }^{8}$ Los tipos de cambio en la estructura laboral se resumen en Mitlin y Satterthwaite, 1996; para Europa se describen con detalle en Wikima, 1993. 
bajos en el petróleo, pues no se ajustan fácilmente a un uso reducido de combustibles fósiles. Muchos de los edificios y formas urbanas industriales, comerciales y residenciales existentes (como los desarrollos suburbanos de baja densidad o los centros comerciales de los suburbios) tienen altos niveles de uso de energía incorporados en su construcción y no son fáciles de cambiar rápidamente (Gore, 1991). Esto significa que hay una cantidad de áreas de consumo crítico que no están determinadas por las preferencias de los consumidores, sino que los individuos están encerrados en patrones de consumo relativamente altos por la infraestructura física sobre la cual tienen poco o ningún control -los sistemas de energía, vivienda, transporte y recolección de basura son ejemplos importantes ( Robins y Roberts, 1996). Resulta complicado que las familias mantengan el compromiso de reciclar si les cuesta trabajo llevar los materiales separados a los centros de acopio. En muchas ciudades del norte es dificil que las familias eviten comprar un coche, si las formas urbanas han cambiado para servir a los automovilistas y no a los peatones, ciclistas o usuarios del transporte público. Muchas de las familias de bajos ingresos del norte tienen las viviendas peor aisladas y las menores posibilidades económicas de solucionarlo. Varias también rentan su casa y no están dispuestas a invertir en mejorías que beneficiarán sobre todo al dueño. Además hay hábitos de consumo que se han desarrollado entre los grupos de clase media y alta y que quizás sean incompatibles con el desarrollo sustentable si se extienden a más de una pequeña minoría de la población mundial -como el gran aumento en el uso de transporte aéreo y el uso generalizado de automóviles particulares para diversión.

Una evaluación inicial de los resultados de Hábitat II en la promoción del desarrollo sustentable en las ciudades

A la luz de la discusión anterior, los dos documentos clave producidos por la conferencia Hábitat II (la declaración de Estambul sobre asentamientos humanos y la Agenda Hábitat) pueden evaluarse en cuanto al grado en que abordan los dos puntos centrales del desarrollo sustentable en las ciudades: una alta prioridad a la satisfacción de necesidades humanas dentro de un fuerte compromiso para minimizar el agotamiento de los cuatro tipos de capital ambiental mencionados en la segunda mitad del cuadro 1 . 
Al hacer esta evaluación debe recordarse que estas grandes conferencias mundiales buscan un consenso entre los representantes de todos los gobiernos presentes. Tanto la declaración de Estambul como la Agenda Hábitat tenían que ser aceptables para los representantes de unas 150 delegaciones gubernamentales, que recibían además considerable presión de grupos tan diversos como la Iglesia católica, la delegación del gobierno de Estados Unidos (y su fuerte oposición, durante gran parte del proceso preparatorio, a que la vivienda se considerara un derecho humano) y las coaliciones feministas y de derechos humanos. Es fácil señalar la falta de precisión en parte del lenguaje utilizado, las repeticiones y la tendencia a formar largas listas de "problemas" con poca consideración de sus vínculos (ni de sus causas subyacentes). Pero esto se puede esperar de documentos que tuvieron que cubrir un área temática tan amplia, incluyendo muchas cuestiones controversiales, y que tuvieron que ser aceptados por representantes de tantos gobiernos tan distintos y con posiciones diferentes, $y$ en los cuales además tantos grupos exigieron o propusieron textos o cambios adicionales a la versión final. Cuando la redacción de un párrafo sobre alguna cuestión controversial resulta poco clara o imprecisa, puede deberse a que una mayor claridad o precisión impedía el acuerdo del representante de algún gobierno o grupo de países. Una de las personas encargadas de redactar el documento reconoció que el primer día de la conferencia se invirtieron casi siete horas para decidir si los asentamientos humanos sustentables "promueven" o "deberian promover" los derechos humanos, y esto es un recordatorio de lo complejo que puede ser llegar a un acuerdo entre tantas partes interesadas (Kakakhel, 1996).

Una primera impresión del tratamiento del desarrollo sustentable y las ciudades en los dos documentos clave podría ser favorable. Tanto la declaración de Estambul sobre asentamientos humanos como la Agenda Hábitat mencionan con frecuencia los "asentamientos humanos sustentables" o el "desarrollo de asentamientos humanos sustentables" -también se menciona varias veces el "desarrollo urbano sustentable". El desarrollo de asentamientos humanos sustentables es uno de los dos temas principales de la conferencia, mientras que el otro es "vivienda adecuada para todos". Además, ambos documentos dan una alta prioridad a la satisfacción de necesidades humanas en las ciudades (y otros asentamientos humanos), incluyendo la necesidad de priorizar la reducción de la pobreza. También enfatizan la necesidad de abordar los problemas ambientales y reconocer los 
importantes componentes de salud al hacerlo. Hay un fuerte acento en la necesidad de fortalecer las autoridades urbanas y municipales.

Sin embargo, los documentos son débiles donde deberían ser más fuertes: al acordar los marcos nacionales e internacionales que asegurarían el seguimiento de las metas del desarrollo sustentable en las ciudades (y otros asentamientos). Como notó uno de los especialistas urbanos más experimentados del Banco Mundial:

La laguna más grande en las discusiones de Estambul fue la falta de progreso para volver operacional la noción de desarrollo ecológicamente sustentable... Si bien el término "desarrollo sustentable" se mencionó repetidamente, hubo poco progreso en sugerir cómo se podría aplicar operacionalmente a las áreas urbanas (Cohen, 1996: 4).

Los documentos de Hábitat II hacen poca mención de los marcos necesarios para lograr reducciones significativas en el agotamiento del capital natural en tre las personas y empresas que actualmente contribuyen más a ello (una alta proporción de las cuales están concentradas en ciudades del norte). De igual manera hace poca mención de los nuevos recursos que deben orientarse a la satisfacción de necesidades humanas en las naciones donde no hay suficientes recursos para lograrlo.

Además, hay una considerable confusión en los documentos de Hábitat II en cuanto a lo que se supone debe sostener el desarrollo sustentable: si son los asentamientos, las políticas de asentamiento o actividades particulares en los asentamientos. Ésta no fue una confusión que surgiera de una búsqueda de consenso durante la conferencia, pues estaba presente en versiones anteriores de lo que se volvió la Agenda Hábitat. En el texto lo que debe sostenerse son a veces los asentamientos húmanos -como en "asentamientos humanos sustentables", "centros urbanos sustentables" o "comunidades sustentables"o agregados de los asentamientos humanos, como en "patrones de desarrollo espacial sustentables". En otras instancias, es la sociedad en general o las condiciones de vida lo que debe ser "sustentable", y en otras, lo que debe ser sustentable son actividades particulares dentro de las áreas urbanas -como en mercados sustentables, desarrollo territorial sustentable, transporte sustentable, agricultura sustentable, vidas sustentables, uso sustentable de recursos, suministro sustentable de agua o uso sustentable de energía. El "crecimiento y equidad económicos sostenidos" también se mencionan como parte del desarrollo sustentable; es evidente que el "crecimiento económico sostenido" 
no es parte del desarrollo sustentable, aunque uno sospecha que lo que quisieron decir los delegados fue que la promoción del desarrollo sustentable no debe inhibir el aumento de los ingresos y de la prosperidad y estabilidad económicas en los países más pobres.

El temor de los delegados gubernamentales del sur de que las medidas ambientales puedan ser mecanismos del norte para inhibir su crecimiento económico sigue siendo fuerte en estas reuniones internacionales -desde que salió a la luz en la conferencia de la onv de 1972 en Estocolmo sobre Medio Ambiente Humano, que inició el ciclo de conferencias mundiales sobre cuestiones de medio ambiente y desarrollo. Lo más que se acercan los documentos de Hábitat II al abordar la pérdida de capital ambiental a causa de los estilos de vida altamente consumistas son algunas referencias al "consumo y patrones de producción no sustentables, particularmente en países industrializados", 9 pero estas referencias no se incluyen en las recomendaciones. Y a pesar de la extensión de los documentos de Hábitat II, no se mencionan los peligros que representa el calentamiento global para los asentamientos, ni la necesidad de frenar las emisiones de gases de invernadero. Quizá los delegados pensaron que esto era innecesario, ya que los documentos endosaban las recomendaciones de conferencias previas, y éstas eran cuestiones tratadas en la Agenda 21, producto de la Cumbre de la Tierra (la conferencia de la onu de 1992 sobre medio ambiente y desarrollo).

Los documentos de Hábitat II también contienen muchos ejemplos donde no son los asentamientos humanos ni sus actividades lo que debe ser sustentable, sino el desarrollo de asentamientos humanos -o políticas particulares de los asentamientos humanos, como en "políticas sustentables de uso de suelo" o "políticas poblacionales más sustentables". A veces es más amplio, como en "actividades sustentables de desarrollo económico y social". Respecto a lo que constituye el desarrollo sustentable, los documentos con frecuencia se refieren a que es una combinación de desarrollo económico, desarrollo social y protección ambiental. ${ }^{10}$ Éstos se mencionan como "componentes interdependientes y mutuamente reforzantes del desarrollo sustenta-

${ }^{9}$ Párrafo 4 de la declaración de Estambul.

${ }^{10}$ Véase el párrafo 3 de la declaración de Estambul, así como los párrafos 4 y 43(b) de la Agenda Hábitat. El párrafo 29 habla de que el desarrollo de asentamientos humanos sustentables asegure "desarrollo económico, oportunidades de empleo y progreso social en armonía con el medio ambiente". 
ble". ${ }^{11}$ Esto resalta otra falla de los documentos: la suposición de que un interés por la calidad ambiental en las ciudades es lo único que se necesita para cumplir con el componente ambiental de las metas del desarrollo sustentable. Lo que falta son los muchos medios por los cuales las empresas y aquéllos con estilos de vida altamente consumistas transfieren algunos de sus costos ambientales a otra gente, otras regiones o al futuro, como se describió en secciones anteriores.

Aunque mucha de la bibliografia sobre desarrollo sustentable puede criticarse por remarcar el mantenimiento del capital ambiental con la virtual exclusión de toda consideración de las necesidades humanas, los documentos de Hábitat II hacen lo contrario. Dos factores ayudan a explicar esto. Lo primero, como ya se señaló, es la manera en que muchas agencias de desarrollo llegaron a usar el término de desarrollo sustentable para etiquetar la seguridad de que sus proyectos de desarrollo seguirían operando cuando se cancelara el apoyo externo de las agencias "al final del proyecto". Aunque éste es un problema que se reconoció antes de que el término se usara ampliamente, muchas agencias internacionales tomaron prestada la nueva terminología, sin considerar su significado original. Lo segundo es el deseo del centro de asentamientos humanos de la oNU (UNCHS), responsable de organizar la conferencia Hábitat II, y de las secretarías de gobierno que tratan con esta agencia -principalmente secretarías de vivienda(Sivaramakrishnan, 1997) de poner las necesidades humanas al centro del "desarrollo sustentable" -en parte como reacción ante el fracaso en este sentido de mucha de la bibliografia sobre el tema. Pero al hacerlo prestan poca atención al hecho de que el desarrollo sustentable también trata de abordar el agotamiento del capital natural (y no sólo de promover la calidad ambiental en los asentamientos). Quizá la evasión de posiciones claras y recomendaciones específicas respecto a las cuestiones más discutibles del desarrollo sustentable sea el precio del consenso. Pero esto significa que los documentos de Hábitat II no incluyen recomendaciones sobre muchos de los puntos esenciales de lo que necesita hacerse para asegurar que se cumplan las metas del desarrollo sustentable en las ciudades (y otros asentamientos).

11 Párrafo 3 de la declaración de Estambul; esto se repite en el párrafo 1 de la Agenda Hábitat, y nuevamente en los párrafos 8 y 43(b); el párrafo 21 menciona al "desarrollo económico, desarrollo social y protección ambiental" como "componentes indispensables y mutuamente reforzantes del desarrollo sustentable". 


\section{Conclusiones}

Este artículo ha esbozado un marco para dar cuenta de una manera más completa del desempeño ambiental de las ciudades, dentro de un compromiso con las metas del desarrollo sustentable. Destaca la importancia de considerar los costos ambientales generados o impuestos por las actividades urbanas a personas o recursos ecológicos que están fuera de los límites de la ciudad, o al futuro. También subraya la importancia de integrar las discusiones sobre ciudades y desarrollo sustentable a las discusiones generales de desarrollo sustentable, así como asegurar que los asuntos urbanos reciban consideración completa en los planes nacionales de medio ambiente y en las estrategias nacionales de desarrollo sustentable.

Dada la tendencia de muchos ambientalistas de concebir a las ciudades como lugares que sólo generan costos ambientales, una excesiva atención a los problemas ambientales de las ciudades también podría ignorar los beneficios que ofrecen (o podrían ofrecer) las empresas y los consumidores urbanos a otras personas, recursos naturales y ecosistemas. Esto incluye desde luego los productos comprados por los consumidores, empresas y gobiernos urbanos, que se traducen en ingresos para los que viven fuera de la ciudad, así como los bienes y servicios que ofrecen las empresas urbanas. También debe tenerse cuidado al culpar a las ciudades de los costos ambientales transferidos a otras personas o ecosistemas, pues son grupos particulares (sobre todo los de ingresos elevados) y empresas particulares los responsables de la mayor parte de tales costos.

Además, no deben olvidarse las ventajas inherentes que tienen o pueden tener las ciudades si se combinan niveles altos de calidad de vida con niveles bajos de uso de recursos, generación de desechos y emisión de gases de invernadero (Mitlin y Satterthwaite, 1996; uNCHs, 1996). Tampoco debe olvidarse que las familias ricas rurales o de los suburbios generalmente tienen niveles más elevados de uso de recursos y generación de desechos que sus contrapartes de la ciudad, porque poseen más automóviles, los utilizan con mayor frecuencia y usan más energía en sus casas (ibid.). Lo que ha buscado subrayar este artículo son las áreas en que es necesario mejorar el desempeño ambiental de las ciudades y cómo estas áreas deben integrarse con las metas sociales, económicas y políticas del desarrollo sustentable. Esto no se logra buscando ciudades sustentables, sino formas en que los consumidores, empresas y gobiernos urbanos puedan contribuir más al desanolio sustentable. 


\section{Bibliografía}

Bairoch, Paul (1986), Cities and Ecomomic Development from the Dawn of History to the Present, Londres, Mansell.

Bartone, Carl, Janis Bernstein, JosefiLeitmann y Jochen Eigen (1994), Towards Environmental Strategies for Cities; Policy Considerations for Urban Environmental Management in Developing Countries, PNUD/ UNCHs/Programa de Manejo Urbano del Banco Mundial, núm. 18, Nueva York, Banco Mundial.

Blowers, Andrew (ed.) (1993), Planning for a Sustainable Environment, Londres, Earthscan.

Breheny, M. J. (ed.) (1992), Sustainable Development and Urban Form, Londres, Pion (Serie European Research in Regional Science, núm. 2).

Cairncross, Sandy, Jorge E. Hardoy y David Satterthwaite (1990), "The Urban Context", en Jorge E. Hardoy, Sandy Cairncross y David Satterthwaite (eds.), The Poor Die Young: Housing and Health in Third World Cities, Londres, Earthscan, pp. 1-24.

Carew-Read, Jeremy, Robert Prescott-Allen, Stephen Bass y Barry Dalai-Clayton (1994), Strategies for National Sustainable Development: A Handbook for their Planning and Implementation, Londres, Earthscan.

Cohen, Michael (1996), "Reflections on Habitat II", grupo de trabajo sobre Hábitat II en el centro Woodrow Wilson, Washington D.C. (mimeo.).

Comisión Europea/Grupo Experto sobre Ambiente Urbano (1994), "European Sustainable Cities", parte 1, documento de trabajo, XI/95/502-en, Bruselas, Comisión Europea.

Comisión Mundial para el Medio Ambiente y el Desarrollo (1987), Our Common Future, Oxford, Oxford University Press.

Conway, Gordon R. y Jules N. Pretty (1991), Unwelcome Harvest, Londres, Earthscan.

Dalai-Clayton, Barry (1996), Getting to Grips with Green Plans: National-Level Experiences in Industrial Countries, Londres, Earthscan.

Diaz, Doris Balvín, José Luis López Follegati y Micky Hordijk (1996), "Innovative Urban Environmental Management in Ilo, Peru", Environment and Urbanization, vol. 8. núm. 1, pp. 21-34.

Douglas, Ian (1983), The Urban Environment, Londres, Edward Arnold.

- (1986), "Urban Geomorphology", en P.G. Fookes y P.R.Vaughan (eds.), A Handbook of Engineering Geomomphology, Glasgow, Blackie \& Son, pp. 270-283.

Drakakis-Smith, David (1996), "Third World Cities: Sustainable Urban Development, Il-population, Labour and Poverty", Urban Studies, vol. 33, núm. 4-5, pp. 673-701.

Goodland, Robert (1995), "The Concept of Environmental Sustainability", Annual Review of Ecological Systems, núm. 29, pp. 1-24. 
Gore, Charles (1991), "Policies and Mechanisms for Sustainable Development: The Transport Sector" (mimeo.).

Hardoy, Jorge E., Diana Mitlin y David Satterthwaite (1992), Environmental Problems in Third World Cities, Londres, Earthscan.

Harrison, Rob (1997), "Ethical Consumption: Bare Faced Cheek", New Inter. nationalist, núm. 289, abril, pp. 26-27.

Hart, Roger (1997), Children's Participation: The Theory and Practice of Involving Young Citizens in Community Development and Environmental Care, Londres, Earthscan.

Haughton, Graham y Colin Hunter (1994), Sustainable Cities, Londres, Jessica Kingsley (Serie Política y Desarrollo Regional).

Jopling, John y Herbert Giradet (1996), Creating a Sustainable London, Londres, Sustainable London Trust.

Kakakhel, B. Shafqat (1996), "To Bracket or not to Bracket: Negotiating the Habitat Agenda", Habitat Debate, vol. 2, núm. 3/4, p. 15.

Leach, Gerald, Christopher Lewis, Frederic Romig, Ariane van Buren y Gerald Foley (1979), A Low Energy Strategy for the United Kingdom, Londres, Science Reviews.

Leduc, James W. y Eugene Tikhomirov (1994), "Global Surveillance for Recognition and Response to Emerging Diseases", Annals of the New York Academy of Sciences, diciembre, pp. 341-345.

Lovins, Amory B. y L. Hunter Lovins (1991), "Least-Cost Climatic Stabilization", Annual Review of Energy and Environment, núm. 16, pp. 433-531.

McGranahan, Gordon, Jacob Songsore y Marianne Kjellén (1996), "Sustainability, Poverty and Urban Environmental Transitions", en Cedric Pugh (ed.), Sustainability, the Environment and Urbanization, Londres, Earthscan, pp. 103-133.

Mega, Voula (1996a), "Our City, our Future: Towards Sustainable Development in European Cities", Environment and Urbanization, vol. 8, núm. 1, pp. 133-154.

(1996b), Innovations for the Improvement of the Urban Environment: Austria, Finland, Sweden, Luxemburgo, European Foundation for the Improvement of Living and Working Conditions Office for Official Publications of the European Communities.

Mitlin, Diana (1992), "Sustainable Development: A Guide to the Literature", Environment and Urbanization, vol. 4, núm. 1, pp. 111-124.

- y David Satterthwaite (1994), Cities and Sustainable Development, trabajo para el Foro Mundial 1994 (Global Forum ‘94), Manchester, Manchester City Council.

- (1996), "Sustainable Development and Cities", en Cedric Pugh (ed.), Sustainability, the Environment and Urbanization, Londres, Earthscan, pp. 23-61.

Organización Mundial para la Salud (oms) (1992), Our Planet, Our Health, reporte de la Comisión de Salud y Ambiente, Ginebra, oms. 
(1996), Creating Healthy Cities in the 21st Century, trabajo del Dialogue on Health in Human Settlements, para Hábitat II, Ginebra, oms.

O'Riorden, T. (1989), “The Challenge of Environmentalism”, en R. Peet y N. Thrift (eds.), New Models of Geography, vol. 1.

Pearce, Fred (1997), "Chill Winds at the Summit", New Scientist, núm. 2071, marzo, pp. 12-13.

Pretty, Jules, Irene Guijt, Ian Scoones y John Thompson (1992), “Regenerating Agriculture; the Agroecology of Low-External Input and Community-Based Development", en Johan Holmberg (ed.), Policies for a Small Planet, Londres, Earthscan, pp. 91-123.

Pugh, Cedric (1996), "Conclusions", en Cedric Pugh (ed.), Sustainability, the Environment and Urbanization, Londres, Earthscan, pp. 229-243.

Rabinovitch, Jonas (1992), "Curitiba: Towards Sustainable Urban Development", Environment and Urbanization, vol. 4, núm. 2, pp. 62-77.

Rees, William E. (1992), "Ecological Footprints and Appropriated Carrying Capacity", Environment and Urbanization, vol. 4, núm. 2, pp. 121-130.

Redclift, Michael (1996), Wasted: Counting the Costs of Global Consumption, Londres, Earthscan.

Robins, Nick y Alex Trisoglio (1992), "Restructuring Industry for Sustainable Development", en Johan Holmberg (ed.), Policies for a Small Planet, Londres, Earthscan, pp. 157-194.

Robins, Nick y Sarah Roberts (1996), "Sustainable Consumption, Inequality and Poverty", Londres, IIED (mimeo.).

Sargent, Caroline y Stephen Bass (1992), "The Future Shape of Forests", en Johan Holmberg (ed.), Policies for a Small Planet, Londres, Earthscan, pp. 195-224.

Satterthwaite, David (1997), "Environmental Transformations in Cities as They Get Larger, Wealthier and Better Managed", The Geographic Joumal, vol. 163, núm. 2, Julio.

—, Roger Hart, Caren Levy, Diana Mitlin, David Ross, Jac Smit y Carolyn Stephens (1996), The Environment for Children, Londres, Earthscan/uniceF.

Schmidt-Bleek, F. (1993), "Mips Revisited", Fresenius Environmental Bulletin, vol. 2, núm. 8, pp. 407-412.

Sen, Amartya (1994), Beyond Liberalization: Social Opportunity and Human Capability, Development Economics Research Programme (DEP), núm. 58, Londres, London School of Economics.

Sen, Gita, Adrienne Germain y Lincoln C. Chen (eds.) (1994), Population Policies Reconsidered, Boston, Harvard University Press.

Sivaramakhrishnan, K.C. (1997), "The Legacy of Habitat II: Issues of Governance", trabajo presentado en la reunión del centro Woodrow Wilson, febrero (mimeo.).

Smit, Jac, Annu Ratta y Joe Nasr (1996), Urban Agriculture: Food, Jobs and Sustainable Cities, Nueva York, PNUD (Serie de Publicaciones para Hábitat II, vol. 1). 
Tischner, Ursula y Friedrich Schmidt-Bleek (1993), "Designing Goods with MiPs", Fresenius Environmental Bulletin, vol. 2, núm. 8, pp. 479-484.

United Nations Comission on Human Settlements (UNCHs) (1996), An Urbanizing World: Global Report on Human Settlements 1996, Oxford, Oxford University Press.

Wackernagel, Mathis y William Rees (1996), Our Ecological Footprint: Reducing Human Impact on the Earth, Cabriola, Canadá, New Society Publishers.

Ward, Barbara (1976), "The Inner and the Outer Limits", Canadian Public Administration, vol. 19, núm. 3, otoño, (The Clifford Clark Memorial Lectures), pp. 385-416.

Wikima Consulting (1993), The Employment Implications of Environmental Action, reporte preparado para la Comisión de Comunidades Europeas, Londres, Dirección General de Empleo, Relaciones Industriales y Asuntos Sociales.

Wohl, Anthony S. (1983), Endangered Lives: Public Health in Victorian Britain, Londres, Methuen. 


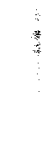

